\title{
O USO DE DOCUMENTOS ESCRITOS NO ENSINO DE HISTÓRIA. PREMISSAS E BASES PARA UMA DIDÁTICA CONSTRUTIVISTA
}

André de Faria Pereira Neto'

\section{RESUMO:}

Este artigo apresenta uma proposta didática de uso do documento escrito no ensino de história. Para tanto, parte de duas premissas para a sua utilização A primeira relaciona-se com a natureza e significado do documento histórico e a segunda como compromisso que o professor de história deve ter com sua prática docente. Cientes da importância destas premissas, o artigo apresenta algumas bases para a utilização deste método didático que interprete o documento escrito de maneira diversa da positivista. Com isso, este artigo pretende auxiliar o professor estimular a curiosidade investigativa e ampliar o desejo pelo conhecimento dos estudantes. Este método pretende ser mais um recurso que ajude o professor a transformar a sala de aula em um lugar de produção de conhecimento escolar.

UNITERMOS: Prática de ensino de História, Métodos didáticos, Uso de documentos históricos.

Alguns professores de História têm percebido que a transmissão do conhecimento não pode mais enfatizar apenas os conteúdos. O professor que obriga o aluno a decorar um amontoado de nomes, datas e conceitos, parece não fazero mesmo sucesso que outrora. As grandes explicações síntese, como o estruturalismo e o marxismo, têm se mostrado, igualmente,

\footnotetext{
I Historiador, Doutor, Professor do Ensino Fundamental das Escola Parque (R.J.) E-mail: <pereiraneton(e hotmail.com> .
} 
artificiais e distantes da realidade do estudante. Além disso, a apresentação do processo histórico como uma seqüência obrigatória e incontestável de acontecimentos ocorridos na Europa, mesmo que associados aos fatos ocorridos no Brasil, tem se mostrado contrária aos princípios construtivistas que orientam os atuais Parâmetros Curriculares Nacionais. Seguindo esta diretriz oficial, o aluno deve ser visto como sujeito do processo educativo e não mais como depositário de um conhecimento já pronto e acabado. Sua experiência e saber, acumulados ao longo da vida, passaram a ser reconhecidos e valorizados. Por estas razões, o uso de documentos escritos no ensino de História tem se tornado uma das práticas mais correntes na sala de aula. A adoção deste recurso didático tem condições de estimular a curiosidade investigativa e o desejo pelo conhecimento, transformando a sala de aula em um lugar de produção de conhecimento escolar. Alguns livros didáticos tem incluído a análise de documentos entre suas atividades. A introdução deste método didático visa auxiliar o estudante a construir conhecimento em história.

O objetivo deste artigo é apresentar algumas premissas para a utilização do documento escrito na aula de história. Que premissas seriam estas? A primeira relaciona-se com a natureza e significado do documento histórico e a segunda como compromisso yue o professor de história deve ter com sua prática docente. Cientes da importância destas premissas, passaremos a apresentar algumas bases de uma proposta didática de análise do documento escrito no ensino de história que afaste-se da maneira positivista de interpretação documental e auxilie o professor a transformar a sala de aula em um espaço de produção de conhecimento em história. 


\section{Documento - Breve história de um conceito}

Documento e Fonte. Para muitos professores de História estas palavras significam a mesma coisa. Para nós, entretanto, esta analogia não parece apropriada. O conceito 'fonte' remete à noção de imanência, de existência autônoma e auto-determinada de algo. A similitude atribuída aos dois vocábulos está relacionada ao sentido que os positivistas quiseram atribuir ao documento - à matriz do conhecimento histórico.

Para a escola positivista, do final do século XIX e início do século XX, a 'fonte primária' passou a ser o fundamento do 'fato histórico'. O papel do historiador, seguindo esta perspectiva, seria de compilar e ordenar documentos, dispondo-os cronologicamente. Para os positivistas a verdade histórica teria condições de vivificar, se as fontes fossem comprovadamente autênticas. A fonte histórica era vista como prova incontestável do vivido.

O documento que para a escola histórica positivista do fim do século XIX e do início do século XX, será o fundamento do fato histórico, ainda que resulte da escolha, de uma decisão do historiador, parece apresentar-se por si mesmo como prova histórica (LE GOFF, 1996, p. 536).

Esta ilusão fez com que o historiador passasse a ser um profissional que perseguisse as 'fontes falsas' e atribuísse, às autênticas, estatuto de verdade incontestável. Os livros escritos por estes historiadores eram repletos de descrições, detalhadas em minúcias, sobre a vida econômica, social e política de uma determinada sociedade ou cidadão. Muitas vezes estes livros reuniam reproduções integrais de documentos. Esta tradição teve visíveis conseqüências no ensino de história. Durante muitos anos, o ensino de nossa disciplina reduziu-se ao ato de memorizar, em ordem cronológica, datas, dados e nomes de personagens 
importantes. Este ensino enfatizava a história dos vencedores, dos reis e imperadores, das guerras e demais acontecimentos associados ao poder político. Além disso ela valorizava o acontecimento em detrimento do processo.

Esta postura filosófica tem sido, há mais de cinqüenta anos, objeto de crítica de diversos autores que trabalham na área da teoria da história. Apesar de não ser este o objetivo deste artigo cahe fazer una menção aos intelectuais que se organizaram em torno da revista 'Annales d'Histoire Économique e Sociale', na França, na primeira metade do século XX. Eles integraram um movimento que se opunha à escola positivista (BURKE, 1991). A luta dos historiadores dos Amnales visava, entre outros objetivos, modificar o significado do conceito 'fonte', tirandothe o sentido de certificado imanente do real. Em vez de enfatizar o sentido de prova testemunhal passou-se a valorizar a dimensão do registro. Estes historiadores queriam que o material escrito deixasse de ser encarado como algo inócuo e passasse a ser visto como uma montagem, consciente ou não, do homem em seu tempo e lugar social e geográfico. Neste sentido constróem a noção de 'documento'.

Eles propuseram, ainda, que fosse feita uma crítica ao 'documento' de ordem diversa àquela implementada pelos positivistas às 'fontes'. Para os historiadores dos Amales a crítica ao 'documento' não deveria se restringir à conferência de sua autenticidade. Para eles o 'documento' passou a ser percebido como uma via, entre outras, que as sociedades encontram para impor determinada imagem de si ao futuro. Assim, o historiador deveria demolir esta montagem, desestruturar esta construção, analisando as condições em que este 'documento' foi produzido (LE GOFF, 1996). Com isso, estes autores, condenaram a passividade e a ingenuidade do historiador diante do 'documento'. 
Os historiadores da 'nova história', como ficaram conhecidos, não restringiram a noção de 'documento' à de registro escrito. Eles alargaram sua abrangência incluindo os objetos de uso pessoal além dos 'documentos' sonoros e iconográficos que pertenceram e serviram ao homem e que portanto, exprimem seus gostos, atividades e maneiras de ser Nesta concepção, o 'documento' não pode ser visto de forma isolada, mas em função à uma série que o precede e sucede (REIS, 1994). Uma outra contribuição que reputamos significativa, à este respeito, relaciona-se com a idéia de sohrevivência do 'documento'. Para os contestadores da lógica positivista em história, há que se levar em consideração que o 'documento' que está em nossas mãos, sobreviveu ao tempo. Outros, muitos outros, não tiveram a mesma sorte. As razões que permitiram esta seleção, consciente ou não, devem ser também objeto de indagação para o historiador. O 'documento', no sentido atribuído por Le Goff (1996) pode ser, portanto, visto como um 'monumento'. 'Documento', pois é fruto de uma escolha do historiador. 'Monumento', pois é um vestígio, um sinal, um lembrança do passado que se faz presente na memória e nos objetos que sobreviveram aó tempo. Não há História sem documentos, é certo, afirma o historiador francês. O historiador deve recuperar os passos deixados pelo homem, isolando-os, tornando-os pertinentes, relacionando-os, constituindo, portanto, um conjunto. Assim a noção do conceito 'documento' distancia-se da de 'fonte', encuanto prova incontestável do vivido.

Esta é uma primeira premissa: o professor que quiser utilizar um documento escrito na sala de aula de história deve afastar-se da tradição positivista que atribui ao documento sentido de prova incontestável de verdade. Ele deve ajudar seus alunos a "demolir esta montagem, desestruturar esta construção e analisar as condições de produção dos documentos-monumentos" (LE GOFF, 1996, p. 548). 
No nosso entender, o documento, em si, não possui qualquer capacidade transformadora e/ou inovadora. O papel que este recurso didático desempenhará depende da forma com que for utilizado. Depende do tipo de compromisso que o professor tiver com o ato de ensinar. $O$ documento pode servir tanto para a ampliação do senso crítico e a construção do conhecimento em sala de aula quanto para consolidar estruturas arcaicas que valorizam a memorização. A utilização adequada do documento na sala depende, sobretudo, do compromisso que o professor tenha com sua prática docente.

\section{O Professor e o Ensino de História}

E....como anda o compromisso do professor com sua prática docente?

No nosso entender prevalece hoje, no magistério do ensino fundamental e médio um crescente desencantamento com a atividade docente.

Este desencantamento está associado, em grande parte, à razões que levaram aquele indivíduo a optar pela carreira docente. Weber (1997) desenha um quadro ao mesmo tempo real e desalentador. Segundo ela, muitos professores optaram pela carreira do magistério por terem se achado vocacionados. Esta emoção subjetiva e romântica se esvai com o tempo, massacrada pelo trabalho sistematicamente desvalorizado e pela enorme carga horária que muitos de nós somos obrigados a cumprir, para sobreviver. Outros professores, segundo a mesma autora, escolheram a carreira do magistério por imposição familiar. Neste caso, o desencantamento com a profissão é mais rápido ainda, pois está associado ao fato do professor não ter tido a oportunidade de decidir seu futuro. O otimismo e entusiasmo, que dominaram 
os primeiros anos de prática profissional, são substituídos por uma progressiva decepção.

Este desencantamento nos parece fruto, ainda, das políticas públicas na área da educação. Não é preciso recorrer aos dados quantitativos para constatar o sistemático desmantelamento do serviço público em nosso país, sobretudo na área da educação nas últimas décadas. Os cortes de verba e o achatamento salarial têm transformado o professor em uma das vítimas deste afastamento criterioso e persistente do Estado da coisa pública. Além (lisso, a carreira de magistério sofre crescente degradação. Muitos profissionais fazem esta opção devido à estabilidade que a condição de funcionário público promove. Sanny Rosa (2000) sintetiza a situação atual do magistério da seguinte forma:

Formados a toque de caixa, em instituições que lidam com o ensino como mercadoria - baixando a qualidade em troca da quantidade - o mercado privilegiado dos egressos do ensino superior seria o magistério público de primeiro e segundo graus. Os haixos salários e as precárias condições de trabalho incumhiram-se de afastar os profissionais mais bem capacitados, passando assim em grande parte às mãos de indivíduos que viram no magistério oficial muito mais uma via de estabilidade de emprego do que propriamente um campo de trabalho exigente quanto ao profissionalismo e seriedade (ROSA, 2000, p. 33).

O perfil social e pedagógico dos alunos que ingressam e permanecem na escola pública, por outro lado, aumenta a frustação de muitos professores. Lá estão crianças mal alimentadas, mal vestidas e com hábitos e experiências muito distantes do universo idealizado pelo professor. Grande parte do corpo discente não tem hábito de leitura, lê mal e escreve de forma bastante deficiente. A sedução que os meios de comunicação de massa exercem, têm afastado a juventude da leitura e da escrita. Os pais destes jovens também não têm 
este hábito. Poucos lêem jornal diariamente. Muito poucos leram algum livro no último ano. O professor de ensino fundamental e médio tem encontrado, muitas vezes, estudantes que escrevem mal, não entendem o que lêem nem o que o professor fala. O desencantamento do magistério com sua prática docente aparece, em parte, como uma decorrência deste quadro.

A questão que nos parece pertinente neste momento é a seguinte: Como o professor tem reagido à este desencantamento?

Uma saída, talvez a mais fácil, tem sido o 'pacto da mediocridade': um acordo velado, não explícito nem formal, entre professor e aluno em que um finge que aprende e outro finge que ensina. Este 'pacto' pode ser materializado de diversas formas. Uma delas é a conhecida 'ficha amarelada': alguns professores carregam em suas pastas aquelas fichas amareladas pelo tempo onde estão escritos o temas, exercícios, esquemas e conteúdos que vêm sendo há anos reproduzidos no quadro negro e copiados pelos alunos. Outra maneira de formalizar este 'pacto' se dá com a má adoção do livro didático. Alguns professores utilizam incorretamente a distribuição gratuita do material didático pelo 'Programa Nacional do Livro Didático (PNLD)'. Em vez de aproveitar este recurso didático de forma crítica e criativa, preferem restringir suas aulas à leitura e memorização de conteúdos presentes neste livro didático O livro didático se transforma assim numa muleta!

A justificativa apresentada pelos professores para tais iniciativas relaciona-se com a falta de apoio institucional decorrente da sistemática estratégia de desvalorização do ensino em nosso país. Se a prática docente é desvalorizada pelo sistema educacional que oferece parcos salários e condições deploráveis de trabalho, ela é igualmente desvalorizada quando o docente abdica do exercício da docência em moldes profissionais e especializados. 
Existe outra maneira de reagir à este desencantamento? Será que o marasmo e a perplexidade dominará todos os docentes?

A participação sindical e partidária, apesar de representar uma via preferencial de atuação política e de transformação desta realidiade, parece sofrer crescente processo de desgaste. Na microlísica de poder (FOUCAULT, 1995) que a escola e sala de aula representam, a autonomia do professor ainda é grande. No nosso entender uma das vias de superação deste desencantamento, pode ser pavimentada, no espaço da escola e da sala de aula. Para tanto o professor deve associar seu compromisso político com uma prática docente voltada para a profissionalização com uma relação com seu aluno, que valorize a construção do conhecimento escolar.

Este compromisso político implica, necessariamente, no abandono das tais 'fichas amareladas' e do livro didático, como uma muleta para o professor. Este compromisso exige que o professor resista às pressões que o empurram para a vala da mediocridade e do autoritarismo. Esta resistência é difícil em tempos de neo-liberalismo! A estratégia de desvalorização docente, implementado por agências nacionais e internacionais, tem obtido êxito na medida em que o desencantamento com a prática docente é aceito como uma situação inevitável. Se somos vítimas desta estratégia neo-liheral, estaremos corroborando com ela ao abdicarmos de um exercício consciente de nosso papel na formação para a cidadania.

Corsetti (2000) reforça a importância do compromisso social do professor de História. Un professor que faz com que sua aula seja agradável e atraente. Um mestre que cria, junto à seus alunos, oportunidades de compreensão da realidade social em toda a sua complexidade. Corsetti (2000) complementa sua idéia afirmando: 
Assumir esse lugar talvez seja a nossa grande possibilidade de contribuir para que nossa sociedade não seja moldada por outros interesses que não sejam os de alcançarmos, com dignidade e solidariedade, um futuro mais justo e melhor para todos (CORSETTI, 2000, p. 22)

Este compromisso político com a prática docente deve estar amparado em estratégias de profissionalização. O profissionalismo e a especialização não são preocupações que orientam o coração e as mentes de muitos docentes desde o momento cue optaram pela carreira do magistério. Alguns professores se conformam com o lugar que ocupam no mercado de trabalho e param de estudar, ler e se aperfeiçoar. Eles estão indo na contramão do reconhecimento profissional! Para uma profissão, seja do cientista ou do professor, adquirir autoridade e autonomia no mercado de serviços há que se especializar e dominar um conhecimento específico (PEREIRA NETO, 1997). O voluntarismo e amadorismo devem ser abandonados. Para transformar a sala de aula em um ambiente propício à construção do conhecimento o professor deve seguir a rota da profissionalização. Este constante processo de aprendizagem pode ser feita tanto em cursos de pós-graduação quanto na própria sala de aula. Nossa experiência docente e nosso contato com os alunos têm muito a nos ensinar. Os cursos de atualização, pós-graduação latu-senso, mestrado e doutorado tem se multiplicado no país, oferecendo alternativas formais de capacitação profissional.

Este compromisso político com a prática pedagógica também implica em uma relação diferente com seu aluno. Acreditamos, como Monteiro (2000), que "cabe ao professor (lemocrático e consciente buscar as alternativas para o trabalho com o aluno real de forma a auxiliá-lo a avançar na construção dos conhecimentos a que como cidadão tem direito" 
(MONTEIRO, 2000, p. 35). Quando Monteiro (2000) se refere ao aluno real está criticando os docentes que, de forma preconceituosa e intolerante discriminam os alunos por serem estudantes que não se adequam à seu modelo ou às suas expectativas.

Nossa sugestão é a seguinte: $O$ professor deve abandonar a forma burocrática e tradicional de lidar com o conhecimentos. Os alunos deverão deixar de ser obrigados a repetir e memorizar conteúdos. A estratégia do professor terá que valorizar a problematização! Segundo Selva S. Fonseca (1997)

\begin{abstract}
A proposta de metodologia do ensino de história cute valoriza a problematização, concebe alunos e professores como sujeitos que produzem história e conhecimento na sala de aula. Logo, são) pessoas, sujeitos históricos que cotidianamente atuam, transformam, lutam e resistem nos diversos espaços de vivência: em casa, no trabalho, na escola (FONSECA, 1997, p. 18)
\end{abstract}

A introdução do documento na sala de aula, pressupõem este compromisso do professor com a prática docente. Ela exige que o professor esteja atento para a função social da escola e para o papel que o ensino da história pode desempenhar para a formação da cidadania. A introdução de documentos na sala de aula depende de um compromisso político que o professor deve fazer ao exercer o magistério em História. O documento não é mágico! Ele, em si, não transforma nada.

A introdução deste recurso didático no ensino de história pressupõem uma nova postura do professor em relação à sua prática. Apresentaremos, a seguir, algumas bases para a utilização de documentos em sala de aula que fuja da tradição positivista tão impregnada em muitos de nós ainda hoje. Esperamos que esta prática docente seja capaz de levar o estudante a 
questionar a realidade/formulando/ problemas e tratando de ressolvê-los, utilizando para isso o pensamento lógico, a criatividade, a intuição, a capacidade de análise crítica, selecionando procedimentos e verificando sua adequação (BRASIL, 1997, p. 14).

\section{O Documento Histórico na sala de aula - bases para sua utilização}

O uso de documentos escritos no ensino de História tem se tornado uma das práticas mais correntes na sala de aula. Para responder à esta crescente demanda alguns livros didáticos tem incluído a análise de documentos entre suas atividades. Esta inserção, entretanto, confere ao documento um papel exclusivamente ilustrativo. Em vez de fazer pensar, de incitar a reflexão crítica e criativa, o documento é apresentado como um exemplo daquilo que o livro texto havia dito. Outras obras têm sido publicadas contendo exclusivamente documentos históricos (INÁCIO e LUCA, 1993; GASMAN, 1976) Estas publicações têm o mérito de disponibilizar documentos históricos, muitas vezes de difícil acesso para o conjunto do professorado. Elas relacionam estes documentos, muitas vezes, sem explicar como e porque eles foram selecionados e sem explicar como o professor deve utiliza-los em sua prática docente.

Uma questão merece destaque neste momento: Como os professores devem utilizar estes documentos? Os pontos, que apresentaremos a seguir, podem servir base para a utilização de documentos na prática docente no ensino fundamental e médio. Utilizaremos 'Carta de Pero Vaz de Caminha', como exemplo, por ser um dos documentos mais utilizados e conhecidos por professores e pela população escolarizada brasileira. 
Primeiro Ponto: O emissor e o receptor

Para fazer uma análise do documento histórico, que fuja da tradição positivista, é preciso desmontar o significado aparente do documento. Uma das vias para esta desmontagem consiste na identificação do emissor e do receptor que o documento se refere. Ou seja, cahe identificar as condiçôes de produção do documento.

Caminha inicia a carta da seguinte forma:

Posto que o Capitão-Mor desta vossa frota, c assim os outros capitães escreveram à Vossa Alteza a nova do achamento desta vossa terra nova, que nesta navegação agora e achou, não deixarei também de dar minha conta disso a Vossa Alteza, o melhor que eu puder, ainda que - para o bem contar e falar -,o saiba fazer pior cue todos.

Tome Vossa Alteza, porém minha ignorância por boa vontade, e creia bem por certo que, para alindar nem afear, não porei ayui mais do que aquilo que vi e me pareceu (CORTESÃO, 1967, p. 199).

Ao analisar as condições de produção de um documento histórico o professor deve levar o aluno a perguntar quem escreveu aquele documento e a quem ele se destinava. Além disso ele deve indagar o sentido geral da produção daquele documento. Assim ele deverá levar em consideração antecedentes do acontecimento que é registrado no documento e seu sentido geral.

No caso da carta de Caminha, cabe lembrar que este documento foi redigido por um escrivão, ou seja, um homem que sahia ler escrever e que exercia seu ofício utilizando este conhecimento tão pouco difundido naquela época. Seu relato dirigia-se ao Rei de Portugal, durante Regime Absolutista. A 
maneira com que Caminha se dirige ao Rei traduz sua condição de submissão. Apesar de Caminha afirmar que falaria a verdade, que não colocaria nada para alindar nem afear, podemos supor que este tenha sido um recurso de retórica utilizado pelo escrivão para atrair a confiança do monarca à sua narrativa.

Todo o documento escrito tem um fim ou um destinatário. Cabe ao professor perguntar para seu alunos, por exemplo, se o início da Carta seria o mesmo se ela se dirigisse à outra pessoa.

Um historiador de matriz positivista, em seu esforço ingênuo de interpretar um documento histórico em sua literalidade, admitiria que Caminha estava falando a verdade. Aceitaria, sem questionar, a versão apresentada por ele. Se a fonte é imanente, se ela atesta o vivido, este historiador diria que Caminha da frota era um homem iria falar ao Rei tudo que aconteceu durante a viagem, sem embelezar nem enfear.

Segundo Ponto. A Relação entre um certo conteúdo disciplinar eo documento

A utilização de um documento histórico pode facilitar, em muito, a compreensão de conceitos abstratos e de difícil compreensão para o jovem estudante. Todo documento histórico, guarda íntima e direta relação com o contexto histórico que o produziu. Sua interpretação pode permitir que o aluno identifique no documento traços de uma determinada época. Esta prática pode aproximar a teoria, sempre fria e abstrata, com a narrativa, sempre rica e impressionante.

Ao estabelecer relações entre o documento e o momento em que foi produzido o professor deve levar o aluno a identificar, no corpo do documento, exemplos que atestem as características mencionadas teoricamente. O documento registra traços essenciais e significativos do contexto histórico que o produziu. 
Voltemos ao exemplo da Carta e Caminha. Todos o professores de história sahem e ensinam que mercantilismo foi uma das características da Era Moderna. Geralmente o aluno é levado a memorizar os objetivos gerais do mercantilismo, sem compreender significado desta política militar e econômica. Com o uso do documento esta compreensão se faz possível de forma atraente.

No momento em que alguns nativos vieram à bordo da nau do Capitão, Caminha fez o seguinte comentário:

\begin{abstract}
Viu um deles uma contas de rosário, brancas. Acenou que thas dessem. Folgou muito com elas e lançou-as ao pescoço. Depois tirou-as e enrolou-as no braço e acenava para a terra e de novo para as contas e para o colar do Capitão, como dizendo que dariam outro por acuilo. Isso assim tomávamos nós por assimo desejarmos (CORTESÃO, 1967, p. 207)
\end{abstract}

Como é do conhecimento geral, o diálogo entre nativos americanos e europeus em 1500 se fez por gestos. A comunicação verbal praticamente não existiu. No trecho, mencionado acima, () Caminha interpreta esta comunicação gestual segundo os interesses maiores que orientaram a expansão marítima. Ou seja, o desejo dos portugueses de acumular ouro e prata se impóe quando Caminha traduz os gestos dos nativo em relação ao rosário de contas brancas. No trecho anterior Caminha, dirigindo-se ao Rei de Portugal, chama a área recém descoberta de vossa terra nova. Caminha não queria saber se a terra já tinha dono ou não. Na mentalidade mercantil isto pouco importava. O que importava era assegurar a posse da terra no discurso e na prática. No discurso esta intenção ficava formalmente assegurada. professor poderia fazer alguma questão à seus alunos que ressaltasse a utilização do pronome possessivo na estrutura do documento. 
Um historiador de matriz positivista, em seu esforço inocente de interpretar um documento histórico admitiria que o Caminha soube muito bem interpretar os gestos dos nativos e que a terra, tão logo descoberta passou a ser do Rei de Portugal.

Terceiro Ponto - A transferência no tempo e no espaço

Uma outra qualidade da utilização de documentos históricos na sala de aula está, a nosso ver, associada ao fato desta prática poder permitir que o jovem leitor se transfira no tempo e no espaço (PAES, 1984). Esta transferência temporal e geográfica tem enormes condições de fazer com que o ensino de história se torne ainda mais atraente para o jovem estudante.

O professor deve propor atividades de análise do documento que permitam ao aluno esta transferência no tempo e espaço. Os julgamentos não históricos em geral estão impregnados de preconceitos. Quando dissemos isso queremos nos referir à alguns professores e pesquisadores que analisam, e estabelecem juízos de valor em relação aos documentos históricos como se eles tivessem sido escritos hoje. O documento histórico é filho de seu tempo! Para ser analisado devemos nos transferir para aquele tempo e espaço para acompanhar-mos suas condições de produção.

Voltemos, mais uma vez, à Carta, mencionando o momento em que Caminha descreve o primeiro encontro entre os portugueses e os nativos. Diz Caminha:

A feição deles é serem pardos, maneira de avermelhados, de bons rostus e bons narizes, bem feitos. Andam nus, sem cobertura alguma. Não fazem o menor calso de encobrir ou de mostrar suas vergonhas, e nisso ten tanta inocência como em mostrar o rostu. Ambos traziam os beiços de baixo furados e metidos neles seus ossos brancos e verdadeiros, do comprimento de uma mão travessa, da grossura dum fuso de algodáo, agudos na ponta como um furador (CORTESÁO, 1967, p. 204) 
A descrição acima está impregnada de preconceitos próprios do pensamento etnocêntrico que dominava os conquistadores da Era Moderna (TODOROV, 1983). Caminha apresenta os aspectos físicos e comportamentais dos nativos que lhe chamaram a atenção, ou seja, os que mais the pareceram diferentes. A perspectiva positivista em história tenderia a incorporar esta narrativa ao discurso cientificista que fundamentou nossa formação racial, em especial à teoria da superioridade do branco em relação ao nativo americano (JOANILHO, 2000).

Uma pergunta deveria ser feita para evitar que o jovem de hoje reproduza o mesmo julgamento preconceituoso do escrivão. Uma pergunta que permitisse estes deslocamento no tempo e no espaço. Uma pergunta que enfatizasse a novidade, que a chegada dos europeus na América, representou para portugueses e para os nativos. Poderia, por exemplo, ser proposto que o jovem leitor se colocasse no lugar do nativo e descrevesse estes portugueses. Esta atividade ficaria ainda mais enriquecida se o professor tivesse em mãos alguma iconografia do século XVI que representasse o homem europeu, sempre vestido dos pés à caheça com pesadas roupas de veludo, ornamentado $\mathrm{com}$ armaduras, medalhas e demais símbolos de poder.

\section{Quarto Ponto: Observar o homem concreto}

Outra qualidade desta prática docente está associada ao fato da utilização de documentos históricos permitir que o aluno entre em contato com o homem real. Neste sentido Maria Helena Paes (1984) ressalta que os documentos tem sido utilizados "com o objetivo de dar vida ao texto didático, às vezes muito frio, despido de emoção, onde a presença do homem concreto dificilmente é percebida pelos alunos de $1^{\circ}$ Grau" (PAES, 1984, p. 51). 
O professor deve selecionar um documento em que a narrativa seja repleta de detalhes que permitam ao estudante apreender a atmosfera da época em que aquele acontecimento foi produzido.

A descrição de Caminha sobre a Primeira Missa rezada no Brasil, pole ser recuperada como um exemplo de narrativa que permite a apreensão do homem concreto.

Ao Domingo de Páscoa pela manhã, determinou o Capitão de ir ouvir missa e pregação naquele ilhéu. Mandou a todos os capitães que se aprestassem nos batéis e fossem com ele. E assim foi feito. E ali com todos nós outros fez dizer a missa, a qual foi dita pelo padre frei Henrique, em voz entoada, e oficiada com aquela mesma voz pelos outros padres e sacerdotes, que todos eram ali. A yual missa, segundo meu parecer, foi ouvida por todos com muito prazer e devoção. Acabada a missa, desvestiuse o padre e subiu a numa cadeira alta e nós todos lançados por essa areia. E pregou uma solene e proveitosa pregação da história do Evangelho, ao fim da qual tratou da nossa vinda e do achamento dessa terra, conformando-se com o sinal da Cruz, sob cujal obediência viemos, o que foi muito a propósito e fez muita emoção (CORTESÃO, 1967, p. 212)

O professor poderia propor a seus alunos uma encenação da primeira missa. Assim o estudante poderia apreender o homem concreto e a situação vivida pela tripulação na manhã do dia 26 de abril de 1500. Desde o início da Carta caminha identifica os dias em yue chegou e saiu de determinado lugar. Para aproximar o jovem estudante da realidade vivida pela tripulação o professor poderia propor yue os alunos fizessem uma linha do tempo identificando os momentos mencionados pelo escrivão.

Um professor de história de matriz positivista, em seu esforço inocente de interpretar um documento histórico admitiria literalmente que missa 'foi ouvida por todos com muito 
prazer e devoção'. O fato do padre ter se desvestido seria encarado com naturalidade deixando de representar a dimensão política da presença da Igreja Católica na expansão marítima.

\section{Quinto ponto: estimular a pesquisa}

Além dos aspectos mencionados acima a análise dos documentos em sala de aula guarda potenciais condições de estimular a prática de pesquisa entre os discentes. Knauss (1999) enfatiza que "a pesquisa é [...] entendida como o caminho privilegiado para a construção de autênticos sujeitos do conhecimento que se propõem a construir sua leitura do mundo" (KNAUSS, 1999, p. 30).

Caminha descreve o teor da reunião entre os capitães presenciada por ele, em que o capitão-mor

[...] perguntou a todos se lhes parecia bem tomar ayui por força um par destes homens para mandar a Vossa Alteza, deixando aqui por eles outros dois destes degredados. [...] Que melhor, muito melhor informação da terra dariam dois homens destes degredados cuue ayui deixassem do cue eles dariam se os levassem, por ser gente que ninguém entende. [...] E que portanto não cuidassem de tomar ninguém por força nem de fazer escândalo, para de todo mais os amansar e pacificar (CORTESÃO, 1967, p. 216).

A presença da Igreja Católica, na Península Ibérica e na América, no período da expansão marítima, foi muito significativa. O Tribunal da Inquisição atuava com rigor e penalizava muitos cristãos-novos com o degredo. A presença da Igreja católica poderia ser objeto de pesquisa tanto a partir do trecho mencionado anteriormente, quando o acabada a missa, o padre desvestiu-se e subiu a numa cadeira alta e fez uma solene e proveitosa pregação da história do Evangelho ou 
no trecho acima quando os degredados eram vistos como peças descartáveis da engrenagem da expansão marítima. Um pesquisa sobre o papel social e político da Igreja Católica durante a expansão marítima poderia ser proposta e ajudaria o estudante a interpretar e compreender o significado mais profundo das palavras e intenções dos capitães da frota dirigida por Cabral.

\section{Considerações Finais}

Assumir uma postura construtivista diante do ensino não se resume a mudanç̧as didático-metodológicas. Implica rever-se como pessoa e como profissional, sem o que aquelas não passarão de 'reformas técnicas' destituídas de qualquer sentido (ROSA, 2000, p. 91).

A preocupação central neste artigo é fazer com que as aulas de história se transformem, cada vez mais, em uma prática pedagógica crítica, atraente e prazerosa para os estudantes do ensino fundamental e médio. Assim, a prática docente baseada na análise de documentos históricos na sala de aula é vista por nós como uma via capaz de auxiliar o professor a transformar a sala de aula em um espaço de produção de conhecimento escolar. Para que este recurso didático cumpra os objetivos mencionados acima é imprescindível o compromisso do professor.

Outros procedimentos metodológicos poderiam ser adotados. Um deles poderia ser o cinema, como prat...ram Soares (1995), Bittencourt (1995) e Pereira Neto ( 1989). A preocupação mais geral relacionada coma natureza do documento histórico e do compromisso do professor seriam mantidas.

Quando apresentamos esta proposta didática reiteramos a posição exposta por Silva e Antonacci (1990) sobre escola e 
ensino como. "palcos de lutas entre diferentes concepções de história e educação" (SILVA e ANTONACCI, 1990). Esperamos que nossa proposta nesta 'luta' tenha ficado clara. Nossa intenção, com este artigo, foi apresentar uma proposta didática para o ensino de história que transforme a sala de aula em um lahoratório de pescuuisas à serviço da ação educativa (PENTEADO, 1988). É o que sonhamos. E sonhos não envelhecem, não é mesmo?

\section{Referências Bibliográficas}

BECKER, F. O que é construtivismo. São Paulo: FDE, 1993.

BITTENCOURT, C. Procedimentos metodológicos em pesquisa sobre imagens no ensino de história. In: ANAIS do II Encontro de Professores Pescuisadores na Área do Ensino de História. Niterói: EDUFF, 1995.

BRASIL. Ministério da Educação. Parâmetros curriculares nacionais. Brasília: MEC, 1997. Volume de História.

BURKE, P. A Revolução Francesa da Historiografia: A Escola dos Annales, 1929-1989. São) Paulo: UNESP, 1991.

CORSETTI, B. Neoliheralismo, memória e ensino de História. In: LENSKIJ, T.; HELFER, N. A memóric e o ensino de histónica. Santa Cruzdo Sul: Edunisc, 2000. p. 12-22.

CORTESÃO, J. A Carta de Pero Vaz de Caminha. Lishoa: Portugália, 1967. FONSECA, S. Caminhlos da história ensinuda. Campinas: Papirus, 1993.

FONSECA, S. O ensino de História e a construção da cidadania. In: SEFFNER, F. (Org.). Qual Históricu? Qual ensino? Qual cidadania? Porto) Alcgre: ANPUH/Ed. Unisinos, 1997. p.14-20.

FOUCAUlT, M. Microfísica do Poder. Rio de Janeiro: Graal, 1995.

GASMAN, L.; FENAME; WEHLING, A. Documentos Históricos Brasileiros. Rio de Janeiro: FENAME, 1976. 
INÁCIO, I. C.; LUCA, T. R. de. Documentos do Brasil Colonial. São Paulo: Ática, 1993.

JOANILHO, A. A construção da nacionalidade. História e Ensino, Londrina, v. 6, p. 131-140, 2000.

KNAUSS, P. Sobre a norma e o óbvio: a sala de aula como lugar de pesquisa. In: NIKITIUK, S. (Org.). Repensando o ensino da História. São Paulo: Cortez, 1999. p. 26-46. (Coleção Questões de Nossa Época; v.53)

LEGOFF, J. Documento/Monumento. In: LE GOFF, J. (1996) História e Memória. Campinas, S.P. : Editora da UNICAMP, 1996. p. 535-553.

MONTEIRO, A. M. Ensino de História: das dificuldades e possibilidades de um fazer. In: DAVIES, N. (Org.). Pura além dos conterudos no ensino de História. Niterói: EDUFF, 2000. p.27-43.

PENTEAI) (), H. 1). Professores e prática pensando a didática. In: ENCONTROS e desenoontros da didática e da prática de ensino. Cadernos CELES, v. 21, p. 6-12, 1988.

PEREIRA NETO, A. História e Cinema em videocassete: reflexões em torno de uma experiência didática. Ciência e Cultura (Revista da Sociedade Brasileira para o progresso da (iência), v. 41, n. 9, p. 884-887, 1989.

PEREIRA NETO, A. Tornar-se cientista: o ponto de vista de Bruno Latour. Cademos de Sande Priblica, v. 13, n. 1, p. 109-118, 1997.

REIS, J. P. Nonvelle Histoire e tempo Histónico: a contribuição de Febvre, Bloch e Braudel. São Paulo: Ática, 1994.

ROSA, S. Construtivismo emudança. São Paulo: Cortez, 2000. (Coleção Questoues de Nossa Épocia; v. 29)

SILVA, M. A.; ANTONACCI, M. A M. Vivências na contramão. Produção de saber histórico e processo de trabalho na escola de $1^{\circ}$ e $2^{2}$ Graus. In: História em Qnadro-Negro. Escola, ensino e aprendizagem. Revista Brasileira de História. São Paulo: ANPUH/Marco Zero, 1990. p. 9-29.

SOARES, M. Cinema como recurso auxiliar do ensino. In: ANAIS do II Encontro de Professores Pesquisadores na Área do Ensino de História. Niterói: EDUFF, 1995. p. 203-214.

TODOROV I. Adescobertada América. A questão do ontro. São Paulo: Martins Fontes, 1983. 
WEBER, S. A desvalorização social do professorado. Contemporaneidade c Educação: Revista Semestral de Ciências e Sociais e Educação, ano II, v. 2., p. $156-170,1997$.

\section{ABSTRACT:}

Sugrgesting the necessity of the usage of written documents at the History teaching practice, this article has a didatical proposal. The text hegins with the explanation of two basic premisses that shows the necessity of its utilization: the first is related with the nature and significance of the historical document itself, while the second one is refered to the commitment that a History teacher shall have with its academic practice. Knowing the importance of these two premises, the article displays some reasons for the usage of this didatic method, so that the written document interpretation will differ from the positivist one. Having this in mind, the article is supposed to help teachers in their work, which is to stimulate the investigative curiosity of their students, increasing their knowledge desire. Therefore, this method intends to be an auxiliar recourse to help teachers to transform the classroom into a place where scholar knowledge is produced.

KEY WORDS: History teaching practice, Lidatic method, Usage of historical written documents. 